This item was submitted to Loughborough's Research Repository by the author.

Items in Figshare are protected by copyright, with all rights reserved, unless otherwise indicated.

\title{
How social workers spend their time in frontline children's social care in
}

\section{England}

PLEASE CITE THE PUBLISHED VERSION

http://dx.doi.org/10.1108/JCS-03-2013-0005

PUBLISHER

(C) Emerald Group Publishing Limited

VERSION

AM (Accepted Manuscript)

LICENCE

CC BY-NC-ND 4.0

REPOSITORY RECORD

Holmes, Lisa, and Samantha McDermid. 2019. "How Social Workers Spend Their Time in Frontline Children's Social Care in England”. figshare. https://hdl.handle.net/2134/12271. 
This item was submitted to Loughborough's Institutional Repository (https://dspace.lboro.ac.uk/) by the author and is made available under the following Creative Commons Licence conditions.

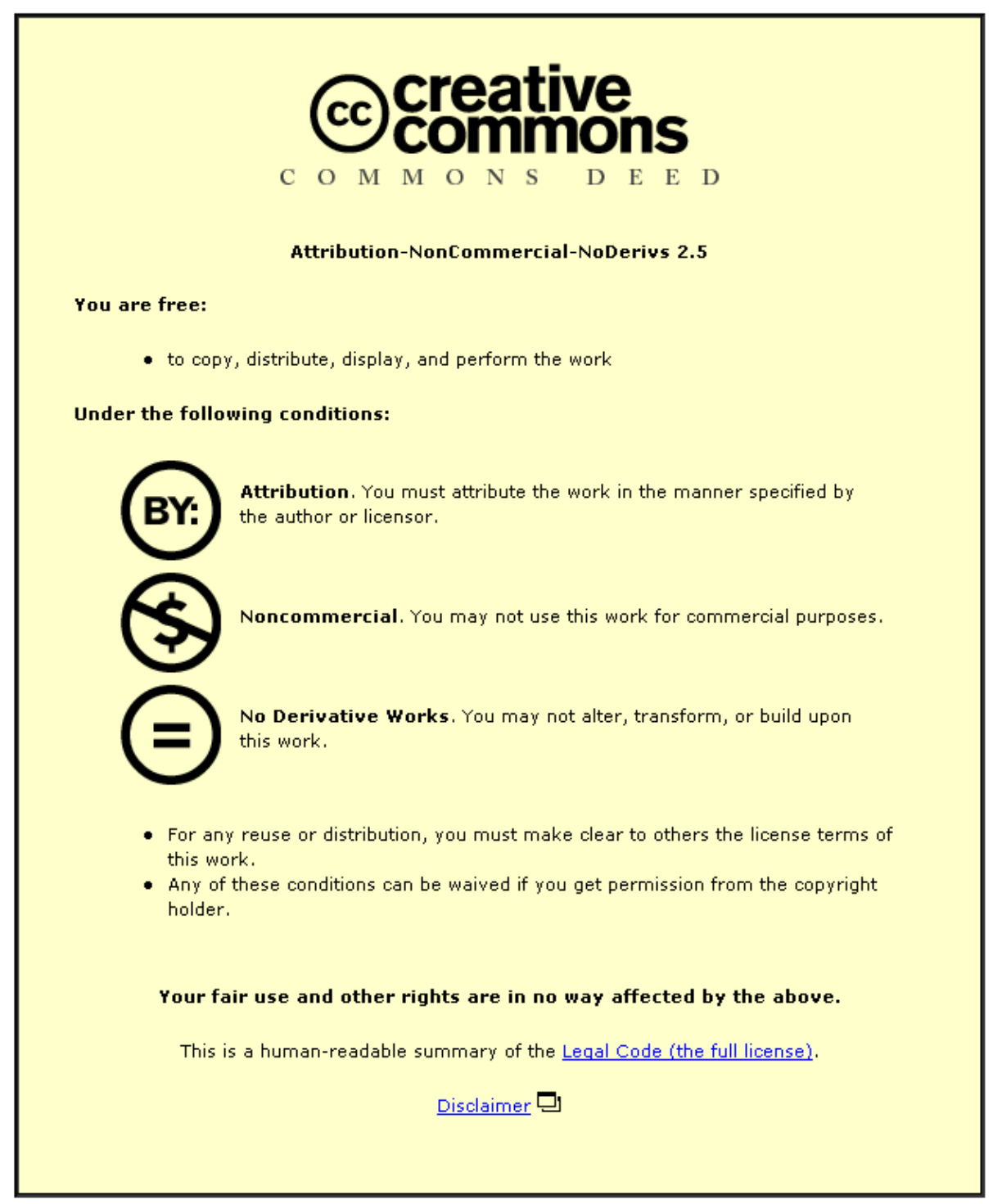

For the full text of this licence, please go to: http://creativecommons.org/licenses/by-nc-nd/2.5/ 


\section{How social workers spend their time in frontline children's social care in England}

Lisa Holmes and Samantha McDermid

Words (5848 including references)

\section{Introduction}

Direct contact with children and their families is a fundamental part of child and family social work. Assessing the needs of families, safeguarding children and the provision on ongoing support is built on direct observation and the development of good relationships between social workers and those they are supporting (Department of Health et al., 2000; Cleaver et al., 2004; Cleaver, 2006). Practitioners are encouraged to develop cooperative, transparent relationships with children and families and decisions about the support they receive, where possible, should be made with their agreement (Department for Children, Schools and Families, 2010). While partnerships between social workers and families are not always possible, especially where there are child protection concerns, evidence suggests that healthy partnerships are associated with better outcomes (Cleaver et al., 2004; Cleaver, 2006; Brandon et al., 2006; Munro, 2011a; Ward et al., 2012). The inclusion of children and young people in direct consultation has also been emphasised and underpinned in legislation (1989 Children Act as amended by section 53 of 2004 Children Act). Furthermore, Working Together to Safeguard Children states that 'some of the worst failures of the system have occurred when professionals have lost sight of the child' (Department for Children, Schools and Families, 2010: 134). The recent review of child protection in England reports that among the crucial features of an effective child protection system is one that is child centred and that prioritises working directly with children and families (Munro, 2011a). Direct contact, therefore, is a significant component for successful child and family social work.

In recent years substantial concerns have been raised in England about the proportion of time social workers have available to spend working directly with families. Many commentators have noted that an increasing administrative burden has been placed on social workers, deflecting them from working directly with children and families (Garrett, 1999; Audit Commission, 2002; Garrett, 2003; Munro, 
2004; Herbert, 2004; Holmes et al., 2009; Munro, 2011a). Some reports suggest that social workers spend between $60 \%$ and $80 \%$ of their time on administrative activities (Herbert, 2004; White et al., 2010). Concerns about the administrative burden placed on front line practitioners are not restricted to statutory children's services: a number of evaluations of the Common Assessment Framework (CAF) have also pointed to the administrative burden placed on professionals when carrying out activities associated with the CAF (Brandon et al., 2006; Norgate et al., 2009; White et al., 2009; Holmes et al., 2012).

However, other studies indicate that the proportion of time spent on administrative tasks may be closer to just under a quarter (Baginsky et al., 2010; Holmes et al., 2010a; Holmes and McDermid, 2012). In a large scale study carried out in 2010, Baginsky and colleagues (2010) found that social workers spent $26 \%$ of their time on direct work with families and $22 \%$ of their time on case recording and administration. This was found to be more or less consistent across social workers from different agencies, although social workers from the private, voluntary and independent sector spent a little less time on case recording. While technologies have changed, Baginsky and colleagues (2010) note that the proportion of social workers' time allocated to administrative tasks has remained consistently at around a quarter since 1972 (Carver and Edwards, 1972; Levin and Webb, 1997; Jacobs et al., 2006) and that 'the proportion of time social workers spend in direct face to face work with clients has remained broadly unchanged' (Baginsky et al., 2010: 11).

This disparity in the estimated proportion of time spent on administrative tasks may be due to definitional differences between different research studies, making direct comparison difficult (Baginsky et al., 2010). Despite conflicting evidence the impact that administrative burden has had on social work with children and families is a central concern and may be precipitated by wider factors, most notably: high profile cases such as that of Peter Connelly; the introduction of targets and performance indicators into child social care practice; and the increased use of information technology within child welfare services. 
A number of high profile cases which attracted substantial media attention, such as the tragic death of Peter Connelly (Department for Education, 2010a; Department for Education, 2010b) and, the subsequent 2009 report by Lord Laming; 'The Protection of Children in England' (Laming, 2009) have brought child protection and the functionality of children's social care into the political spotlight. National policy in England has emphasised the need to critically examine children's social care and ensure that social workers and the structures that support their work are fit for purpose. As such, the recent comprehensive review of Child Protection carried out by Professor Munro was commissioned for this purpose (Munro, 2010; Munro, 2011a; Munro, 2011b).

That review, along with other authors, note that well intentioned attempts to improve social work practice through the introduction of targets and performance indicators have led to a focus on monitoring and auditing cases, requiring front line workers to record substantial amounts of data for both National Returns and to ensure their own professional accountability (Burton and van den Broek, 2008; Munro, 2010; Munro, 2011a; Gillingham, 2012). This has been compounded by criticisms of the electronic recording systems through which such targets are evidenced. The design of electronic recording systems, which also serve as daily case records for frontline workers, have been widely criticised as not being fit for purpose and increasing the time required to update records (Bell et al., 2007; Seneviratna, 2007; Holmes et al., 2009; Shaw et al., 2009; Broadhurst et al., 2010).

This paper brings together the findings from research carried out as part of the costs and outcomes programme by researchers at the Centre for Child and Family Research (CCFR), Loughborough University. The focus of this paper is the reported social care activity to support children in need as defined by Section 17 of the 1989 Children Act and those subject to a Child Protection Plan. As part of a methodology to calculate unit costs, time use activity data has been gathered from a range of social care professionals. This time use activity data includes a detailed breakdown of the proportion of time spent on direct client contact and other activities such as case recording and administrative tasks. This paper will also explore wider practice issues which have been reported to impact on the time required to undertake 
administrative tasks and the time available to spend working directly with children and their families.

\section{Methodology}

The costs and outcome research programme has explored the relationship between needs, costs and outcomes for a range of child welfare interventions. The research team have utilised a 'bottom up' methodology for the estimation of unit costs (Beecham, 2000). This methodology has been deployed across a number of studies to calculate the costs of placing looked after children (Ward et al., 2008), supporting children in need (Holmes et al., 2010b; Holmes and McDermid, 2012) and the Common Assessment Framework (Holmes et al., 2012). The research has also enabled the collation of contextual practice information from frontline workers, operational and commissioning managers and other social care staff regarding the changing nature of front line social work practice, and has been used to explore key policy and practice developments (Holmes et al., 2010a).

The unit cost estimation method uses the activities undertaken by professionals working with children and families as the basis of building up costs from the "bottom up' (Beecham, 2000). These activities are broken down into their most discrete components and are organised into groups of processes associated with the different types of support provided to children and their families (Ward et al., 2008; Holmes and McDermid, 2012). The activities associated with case work have been divided into two distinct categories: 'direct work' with children and their families, including both face-to-face meetings and telephone calls and 'indirect work', including attendance at meetings, case recording along with administrative tasks such as the completion and distribution of minutes from meetings. The sets of processes identified for children in need are shown in Box 1. The time use activity data collected for these processes forms the basis of the analysis included in this paper.

INSERT BOX 1 ABOUT HERE

Cite as: Holmes, L. and McDermid, S. (2013) How social workers spend their time in frontline social care in England. Journal of Children's Services: research informing Policy 8(2) 
Data were collected about the time taken by each type of social care professional to complete the activities associated with the processes shown in Box 1. Data were gathered from four English local authorities between 2008 and 2010 as part of a study to explore the costs of providing services to children in need and those subject to a Child Protection Plan (Holmes et al, 2010). The local authorities were selected based on the percentage of overall expenditure allocated to children in need and included one inner London authority, one Shire County and two metropolitan boroughs.

A series of focus groups with social work practitioners were carried out. A total of 79 professionals participated in the focus groups. The purpose of the focus groups was to estimate the average time taken to complete the tasks associated with the processes (as outlined in Box 1). The discussions elicited through the focus groups were also used to identify variations in the time taken to complete these activities according to the different needs and circumstances of the child and their family. The data gathered through the focus groups were verified via verification questionnaires completed by 71 professionals. Additional time use data was provided by thirty five social workers that completed event records detailing all their activity for a specific case over a time period of up to three months. Workers were asked to record the type of activity undertaken, which of the eight social care processes it related to and the time taken to complete that activity.

The data from the focus groups, verification questionnaires and event records were triangulated to calculate an average time for each activity and process, for children with different types of needs. Bringing together the data from the multiple sources increases the sample size and therefore the reliability and validity of the data (Becker and Bryman, 2012). The time use activity data were cleaned, with each of the activity types across processes being subjected to frequency tests and any incorrect, missing or unusual entries were investigated. Once these checks had been undertaken outliers were removed for each of the types of activities across the processes. The time use activity data were also verified using 'scenarios' to ensure that the reported activity times do not exceed or fall behind what can reasonably be achieved within the average working month or average case load (Holmes and McDermid, 2012). 


\section{Findings}

The following section of this paper explores the time spent on the different types of activities for the processes to support children in need. While all professionals will undertake other activities such as team meetings, training and supervision, these have been excluded from the analysis presented in this paper. These activities, however, have been accounted for in verification calculations (Holmes and McDermid, 2012).

All of the processes carried out to support children in need, except Process 3 ('ongoing support') are discrete processes. While these processes may occur more than once within an episode of support, they each have distinct start and end points. In contrast Process 3 is associated with the ongoing support provided by social care workers and is a continuous process. Time use activity data were collected on a monthly basis for this on-going process.

Breaking down the activity into these processes facilitates an exploration and analysis of the proportion of time spent on the different types of tasks. The proportion of reported times spent on the eight children in need processes, broken down into direct, indirect and administrative activities are displayed in Table 1.

\section{INSERT TABLE 1 ABOUT HERE}

As Table 1 shows the proportion of time spent on direct and indirect activities varies according to the types of process. The process associated with the ongoing support of families has the highest proportion of direct activity; while processes associated with decision making, such as assessments, planning and review, have the highest reported proportions of administrative activities. The higher proportion of administrative activities can be attributed to the reports required for the completion of these processes.

It is unlikely that a social worker's day to day activity will be evenly spread across the different processes. The 'one off' processes are associated with the highest proportion of administrative activity and while some of these processes occur at 
regular intervals, some are likely to occur less frequently. For instance, assessments are undertaken in the early stages of an episode or when circumstances change. There may be times when higher levels of administrative activity are required as part of the completion of reviews or assessments for a number of children on a case load. Conversely some families may need intensive levels of direct contact as they experience difficult circumstances.

Furthermore, the proportion of time spent on the different type of activities is likely to vary across teams. Some teams may spend the majority of their time on just a few of the processes. For instance, many local authorities have specific teams for the referral and assessment of children and families ('Duty Teams') who typically undertake the majority of Process 1 (Initial contact and referral), 2 (Initial Assessment), 5 (Core Assessment) and 7 (Section 47 Inquiry). Cases may then be allocated a social worker within another team who may undertake the majority of the remaining activities. While the division of processes between teams is not exclusive, it may mean that the administrative burden is disproportionately placed on some types of teams compared to others within Children's Services Departments.

Previous research has found that the time required to complete case management processes varies according to the needs and characteristics of the children and/or family (Ward et al., 2008; Holmes and McDermid, 2012). The constituent pattern of the activities and processes also varies according to different needs. The time use activity data outlined in Table 1 was used alongside detailed case record information for a sample of 180 children in need over a six month time period. Using these data it was possible to explore differences in the levels of ongoing support (Process 3) offered to children with different circumstances and differing levels of need.

A number of factors were found to be associated with increased levels of ongoing support: the child being subject to a Child Protection Plan; being aged under six; having emotional and/or behavioural difficulties (EBD); or a combination of these factors. Table 2 shows the proportions of time spent on providing ongoing support to children in each of these categories.

\section{INSERT TABLE 2 ABOUT HERE}

Cite as: Holmes, L. and McDermid, S. (2013) How social workers spend their time in frontline social care in England. Journal of Children's Services: research informing Policy 8(2) 
In general, children with additional needs or combinations of needs received more direct ongoing contact from a social worker than those with no identified additional needs. However, less time was spent in direct contact (visits) with children with EBD than with children in the other needs categories. For these children a higher proportion of time (26\%) was spent liaising with other professionals.

The data presented in Table 2 show the proportions of activity associated with ongoing support. The activities associated with other processes such as reviews and assessments are not included, however, and there is evidence to suggest that administrative activities for assessments, planning and review also increase with the needs of the child and family. For instance, administrative activities for a Child Protection Case Conference Review constitutes 75\% of the overall activity compared to $49 \%$ for a Child in Need review (Holmes et al., 2010b).

It is evident that understanding the proportion of time spent on direct and indirect activities is complex. While the data suggest some social work activities, such as the Core Assessment have a large administrative constituent, overall the proportion of time allocated to administrative activities, for the sample cases at least, falls below the figure 60 -80\% reported in other studies (White et al., 2010). The constituent pattern of activities may vary depending on ebb and flow of case work, the process being undertaken or on the needs and characteristics of the case. However, it remains evident from the extent of the concerns raised in current policy and research that the administrative burden placed on front line professionals and the impact that is having on the time available for direct work with families is a pertinent question for practice and policy. The remainder of this paper will explore the impact of the current context within which these concerns have been expressed and how the findings of this and other research can be used to inform policy and practice.

\section{Discussion}

Central to concerns about the administrative burden placed on social care professionals is the impact that this might have on the availability of time to carry out direct client contact (Audit Commission, 2002; Garrett, 1999; Garratt, 2003; Herbert, 2004; Holmes et al., 2009; Munro, 2004; Munro, 2011a). Furthermore, extensive administrative duties have been linked to deficiencies in the child protection system, 
undermining safe professional practice and increasing risk (Munro, 2011a; White et al., 2010). However, in order to understand the capacity of the child protection system to effectively safeguard and support children and families the impact of wider factors on social care practice need to be taken into consideration.

Research evidence has suggested that high profile cases, such as that of Peter Connelly, have impacted on the workloads and morale of workers (Social Work Task Force, 2009; Holmes et al., 2010a; Munro, 2011a). Local authorities have seen greater levels of anxiety with regards to the safeguarding of children among social care practitioners and colleagues working in other agencies (Holmes et al., 2010a; Holmes et al., 2012). While the number of children referred to social care has been steadily rising over recent decades, this rise has accelerated since the publicity around the death of Peter Connelly (Munro, 2010). Department for Education statistics show there was an $11 \%$ increase in referrals in the year after the death of Peter Connelly and a further $10.4 \%$ increase in the following year (Department for Education, 2010c). The numbers of referrals to social care continued to rise in 2011 (Department for Education, 2011). A study published by the Association of Directors of Children's Services (ADCS) based on responses from 105 local authorities found that there had been an increase of $20.3 \%$ in the number of Section 47 Inquiries being undertaken, and a $32.9 \%$ increase in the number of children subject to a Child Protection Plan (Brookes, 2010). Frontline practitioners working in referral and assessment teams reported that they had received an increased number of referrals that were not considered to meet the threshold for social care intervention, which they considered to be taking time away from effectively completing assessments for those that did meet the threshold, along with placing undue anxiety on vulnerable families (Holmes et al., 2010a; Munro, 2011a).

This is further compounded by difficulties recruiting new social workers to the profession (Brookes, 2010). The Social Work Task Force noted that 'social workers feel that their profession is under-valued, poorly understood and under continuous media attack. This is making it hard for them to do their jobs and attract people into the profession' (Social Work Task Force, 2009). However, a recent study suggests that vacancy rates had begun to fall across Britain in 2011 (McGregor, 2011). Under such conditions, frontline workers have also expressed concerns regarding their own 
capacity to complete all the tasks necessary for high quality assessments (Baginsky et al., 2010; Holmes et al., 2010). Holmes and colleagues (2009) found that total number of hours worked had risen between 2001 and 2008 and there is evidence to suggest that social workers regularly work up to 10 hours a week over and above their contracted hours (Baginsky et al., 2010; Holmes et al., 2009). While a number of authorities operate a system of 'time off in lieu' (TOIL), where workers are entitled to take any additional hours worked over their contracted time off as leave, workers anecdotally report that they rarely able to take some or all of their TOIL (Holmes et al., 2009).

The research reported in the previous paragraph highlights an increase in referrals to children's social care in recent years. As shown in Tables 1, it is these activities associated with Process 1 that constitute high levels of administrative, and indirect activities (only 32\% of Process 1 is reported to be spent on direct work with children and families). Front line workers and managers have reported that such an environment has increased the burden placed on social care referral and assessment teams in particular. There is also evidence to suggest that for some teams the level of administrative support has been reduced as part of structural reorganisations. In these instances social workers were carrying out administrative tasks such as booking rooms for meetings, arranging meetings, sending documentation to colleagues in other agencies, and workers expressed concerns about whether this was the best use of their time (Ward et al., 2008; Holmes et al 2009; Holmes et al., 2010a). Additional workloads, combined with a reduction in clerical support will impact the level of administrative activity undertaken by front line staff.

As noted in the introduction, research suggests that the unintended consequences of attempts to improve children's social care have resulted in a system dominated by accountability, targets and performance indicators (Burton and van den Broek, 2008; Munro, 2010; White et al., 2010; Munro, 2011a; Gillingham, 2012). The Munro review of child protection suggests that recent reforms to improve accountability among Children's services Departments have had unintended consequences of the bureaucratisation of social work, the emphasis on top down regulation to the detriment of empowering social workers to autonomously exercise judgement based 
on their training and rapport with individual families (Munro, 2010; 2011a). Critics have argued that there is increasing pressure on children's social care professionals to demonstrate good practice through targets, performance indicators and timescales, which must be evidenced through case recording (Burton and van den Broek, 2008; Gillingham, 2012; White et al., 2010).

The increased emphasis on the importance of case recording has been compounded since the introduction of electronic recording systems (Bell et al., 2007; Broadhurst et al., 2010; Holmes et al., 2009; Seneviratna, 2007; Shaw et al., 2009). While information technology has been implemented to introduce efficiencies (White et al., 2010; Gillingham 2012), barriers have arisen due to the challenges in designing management information systems that both reflect the needs of those inputting the data (front line workers) and that produce appropriate outputs (McDermid, 2008; Scott et al., 2005). Although, robust and reliable data are required if children's services' commissioning strategies and the assessment of outcomes are to be effective and UK child level data collections are internationally recognised as providing valuable longitudinal data (Munro et al., 2011) the systems need to be designed to ensure that the data are available without placing undue burden on frontline workers (Scott et al., 2005; McDermid, 2008). Baginsky and colleagues (2010) found no differences in the proportion of time spent on administrative activities between those workers using electronic recording systems and those using paper records, suggesting that the extensive implementation of electronic records has not produced the efficiencies originally anticipated. It has been reported that electronic exemplars are too complex, repetitive, time consuming to complete, and fail to reflect practice (Gillingham, 2012; Holmes et al., 2009; White et al., 2010). Furthermore, limited access to computers or remote access to management information systems has also presented difficulties for front line social care professionals (Holmes et al., 2009).

Despite the additional emphasis placed on case recording there is evidence to suggest that social care professionals prioritise direct contact with families. Workers reported frequently completing administrative activities either on evening and weekends in order to ensure that sufficient levels of direct contact with families are maintained (Holmes et al., 2010a). 
Since the completion of the research project outlined in this paper there have been a number of proposed policy and practice changes to children's social care in England. The government has recently proposed to enable Children's Services Departments to move away from a 'culture of compliance by reducing central prescription and placing a greater emphasis on the appropriate exercise of professional judgment' (Department for Education, 2011c:13).

In response to the Munro review of child protection in England (Munro, 2011a) the statutory guidance for the safeguarding of children has been revised. This revised guidance seeks to simplify and clarify the processes for front line social care workers (Department for Education, 2012). Between March and September 2011 the Secretary of State for Education issued formal directions to eight English local authorities to test more flexible assessment processes, including the use of a single assessment in place of initial and core assessments

It is currently unclear how these practice and policy changes will impact on the constituent proportions of time spent on different types of activities by frontline social workers. However, a recent evaluation of the impact of the flexible assessment practices introduced in the eight trial authorities (Munro and Lushey, 2012) provide some emerging evidence about the impact on front line practice. Munro and Lushey report that views are mixed about whether the flexible assessment processes provide more opportunities for direct work with children and their families:

'While some social workers perceived that the single assessment had reduced the time spent on case recording, thus freeing up more time for targeted work where appropriate: others thought that the flexibilities meant they were collecting more information which in turn needed to be analysed and recorded, thus offsetting any gains from a streamlined assessment process' (ibid: 8).

\section{Conclusion}

Cite as: Holmes, L. and McDermid, S. (2013) How social workers spend their time in frontline social care in England. Journal of Children's Services: research informing Policy 8(2) 
The proportion of time social workers spend on direct client contact and administrative tasks is complex. The constituent pattern of case related activity is affected by both the type of process undertaken and the needs and characteristics of the child or families for whom it is undertaken. The data in this paper suggest that these complexities have not fully been accounted for in previous research. Observed increases in administrative activity may reflect a complex relationship between the type of work social workers are required to do and wider changes to the sector, rather than workers simply being required to complete more paper work. While it is evident that some social care activities do require a large component of administrative activity, there is also evidence to suggest that direct work with families has also increased and is prioritised by social care professionals. It would appear that the workloads of social care professionals have increased per se and these difficulties have been compounded by a complex configuration of interrelated and overlapping factors.

The findings outlined in this paper indicate that it may be advantageous to consider whether an administrative burden is being disproportionally placed on some children's social care teams in England, for example initial contact and referral teams. An exploration of the differing levels of administrative burden within local authorities may highlight how and where administrative resources could be reconfigured.

\section{References}

Audit Commission (2002) Recruitment and Retention: A Public Service Workforce for the 21st Century, London: Audit Commission.

Baginsky, M., Moriarty, J., Manthorpe, J., Stevens, M., Maclnnes, T., and Nagendran T. (2010) Social Workers workload survey: Messages from the frontline, London: Department for Children, Schools and Families.

Beecham, J. (2000) Unit Costs - Not Exactly Child's Play: A Guide to Estimating Unit Costs for Children's Social Care, Kent: University of Kent, Department of Health, Dartington Social Research Unit and the Personal Social Services Research Unit.

Becker, S. and Bryman, A. (2012) Understanding Research for Social Policy and Practice: Themes, methods and approaches ( $2^{\text {nd }}$ Edition), Bristol: The Policy Press. 
Bell, M., Shaw, I., Sinclair, I., Sloper, P. and Rafferty, J. (2007) The Integrated Children's System: An Evaluation of the Practice, Process and Consequences of the ICS in Councils with Social Services Responsibilities, York: Department of Social Policy and Social Work, University of York.

Brandon, M., Howe, A., Dagley, V., Salter, C. And Warren, C. (2006) What appears to be helping or hindering practitioners in implementing the Common Assessment Framework and Lead Professional working? Child Abuse Review, 15 pp. 396-413.

Broadhurst, K., Wastell, D., White, S., Hall, C., Peckover, S., Thompson, K., Pithouse, A., and Davey, D. (2010) Performing Initial Assessment: identifying the latent conditions for eError at the front-door of local authority children's services, British Journal of Social Work, 40 (2) pp. 352-379.

Brookes, C. (2010) Safeguarding pressures projects: results of data collection, London: Association of Directors of Children's Services.

Burton, J. and van den Broek, D. (2008) Accountable and countable: information management systems and bureaucratization of social work, British Journal of Social Work, 37, 7, pp. 1326-1342.

Byford, S., and Fiander, M. (2007) Recording professional activities to aid economic evaluations of health and social care services. In: Curtis, L., (ed) The Unit Costs of Health and Social Care 2007, Kent: Personal Social Services Research Unit, University of Kent.

Carver, V. and Edwards, J.L. (1972) Social Workers and their Workloads, London: National Institute for Social Work Training.

Children Act 2004, London: Her Majesty's Stationery Office.

Children Act 1989, London: Her Majesty's Stationery Office.

Cleaver, H. (2006) The influence of parenting and other family relationships, In: Aldgate, J., Jones, D., Rose, W., and Jeffery, C. (eds) The developing world of the child, London: Jessica Kingsley Publishers.

Cleaver, H. and Walker, S. with Meadows, P. (2004) Assessing Children's Needs and Circumstances. London: Jessica Kingsley Publishers. 
Department for Children, Schools and Families (2010) Working Together to Safeguard Children: A guide to inter-agency working to safeguard and promote the welfare of children. London: Department for Children, Schools and Families.

Department for Education (2010a) Serious case review 'child a' November 2008, London: Department for Education.

Department for Education (2010b) Serious case review 'child a' March 2009, London: Department for Education.

Department for Education (2010c) Children Assessed To Be In Need By Children's Social Services, England, 6 Months Ending 31 March 2010. London: Department for Education.

Department for Education (2011a). Characteristics of Children in Need in England, 2010-11 London: Department for Education. Available online at: http://www.education.gov.uk/rsgateway/DB/STR/d001041/index.shtml last accessed on $25 / 1 / 12$

Department for Education (2012) Working Together to Safeguard Children: Draft guidance. London: Department for Education. Available online at: https://www.education.gov.uk/aboutdfe/departmentalinformation/consultations/a0021 $\underline{1065 / \text { revised-safeguarding-guidance }}$

Department of Health, Department for Education and Skills and The Home Office (2000) Framework for the Assessment of Children in Need and their Families, London: The Stationery Office.

Garrett, P.M. (1999) Producing the moral citizen: the 'Looking After Children' system and the regulation of children and young people in public care, Critical Social Policy, 19, pp. 291-311.

Garrett, P.M. (2003) Swimming with dolphins: The Assessment Framework, New Labour and new tools for social work with children and families, British Journal of Social Work, 33 (3), pp. 441-463.

Gillingham, P. (2012) The development of electronic information systems for the future: practitioners 'embedded structures' and technologies-in-practice, British Journal of Social Work: Advanced online access.

Herbert, I. (2004) 'Pressure of paperwork stops social workers from working', The Independent Online 30.04.2004, available at http://www.independent.co.uk/ . 
Holmes, L., and McDermid, S. (2012) Understanding Costs and Outcomes in Child Welfare Services: A Comprehensive Costing Approach to Managing Your Resources, London: Jessica Kingsley Publishers.

Holmes, L., McDermid, S., Jones, A. Ward, H. (2009) How Social Workers Spend Their Time: An Analysis of the Key Issues that Impact on Practice pre-and post implementation of the Children's Integrated System, London: Department for Children, Schools and Families.

Holmes, L., McDermid, S., Padley, M., and Soper, J. (2012) An exploration of the costs and impact of the Common Assessment Framework, London: Department for Education.

Holmes, L., McDermid, S., Soper, J., Sempik, J. and Ward, H. (2010b) Extension of the Cost Calculator to Include Cost Calculations for all Children in Need: Research Brief, London: Department for Education.

Holmes, L., Munro, E.R., and Soper, J. (2010a) The costs and capacity implications of implementing Laming (2009) recommendations, Loughborough: CCFR, Loughborough University.

Jacobs, S., Hughes, J., Challis, D., Stewart, K. and Weiner, K. (2006) From care management to case management: what can the NHS learn from the social care experience? Journal of Integrated Care, 14(3) pp. 22-31.

Laming, The Lord (2009) The Protection of Children in England: A progress report. London: The Stationery Office.

Levin, E. and Webb, S. (1997) Social Work and Community Care: Changing Roles and Tasks, London: National Institute for Social Work.

McDermid, S., (2008). The nature and availability of child level data on children in need for use by Children's Services practitioners and managers. Research, Policy and Planning, 26(3) pp. 183-192.

McGregor, K., (2011) 'Social worker vacancy rates down across Britain', Community Care Online 20.09.11, available at http://www.communitycare.co.uk/Articles/20/09/2011/117476/social-worker-vacancyrates-down-across-britain.htm.

Munro, E. (2004) 'The impact of audit on social work practice', British Journal of Social Work, 34 (8), pp. 1075-1095. 
Munro, E. (2010) The Munro Review of Child Protection Part One: A Systems Analysis. London: Department for Education.

Munro, E. (2011a) The Munro Review of Child Protection Final report. London: Department for Education .

Munro, E. (2011b) The Munro Review of Child Protection Part One: Interim Report: The child's journey. London: Department for Education.

Munro, E.R., Brown, R., Sempik, J., and Ward, H., with Owen, C. (2011) Scoping review to draw together data on child injury and safeguarding and to compare the position of England with that in other countries, Report to the Department for Education, London: Childhood Wellbeing Research Centre, Institute of Education, University of London., Centre for Child and Family Research, Loughborough University., PSSRU, University of Kent.

Munro, E.R. and Lushey, C. (2012) The impact of more flexible assessment practices in response to the Munro Review of Child Protection: Emerging findings from the trials, London: Childhood Wellbeing Research Centre, Institute of Education, University of London., Centre for Child and Family Research, Loughborough University., PSSRU, University of Kent.

Norgate, R., Traill, M., and Osbourne, C. (2009) Common Assessment Framework (CAF) - early views and issues. Educational Psychology in Practice. Vol 25(2) pp..139-150.

Scott, J., Moore, T., \& Ward, H. (2005) Evaluating Interventions and Monitoring Outcomes, in Scott, J., \& Ward, H. (eds.) Safeguarding and Promoting the Wellbeing of Children, Families and Communities, London: Jessica Kingsley Publishers, pp.. 262 - 273

Seneviratna, C. (2007) 'Cutting the red tape: moves to slash social workers' paperwork', Community Care Online 04.10.2007, available at http://www.communitycare.co.uk/Articles/2007/10/04/105987/cutting-the-red-tapemoves-toslash-social-workers-paperwork.html . 
Shaw, I., Bell, M., Sinclair, I., Sloper, P., Mitchell, W., Dyson, P. and Rafferty, J. (2007) 'An Exemplary Scheme? An Evaluation of the Integrated Children's System', British Journal of Social Work, 39, pp. 613-626.

Social Work Task Force (2009) Building a Safe and Confident Future- The Final Report of the Social Work Taskforce. London: Department for Children, Schools and Families

Ward, H., Holmes, L., and Soper, J. (2008) Costs and Consequences of Placing Children in Care. London: Jessica Kingsley Publishers.

Ward, H., Brown, R., Westlake, D. and Munro, E.R. (2012) Safeguarding Babies and Very Young Children from Abuse and Neglect. London: Jessica Kingsley Publishers.

White, S., Hall, C., and Peckover, S. (2009) 'The Descriptive Tyranny of the Common Assessment Framework: Technologies of Categorization and Professional Practice in Child Welfare'. British Journal of Social Work, 39 (7), pp. 1197-1217.

White, S. Wastall, D., Broadhurst, K., and Hall, C. (2010) When policy o'leaps itself: The tragic tale of the Integrated Children's System. Critical Social Policy Vol 30(3) pp. $405-429$. 


\section{Citation:}

Holmes. L., and McDermid, S. (2013). How social workers spend their time in frontline children's social care in England. Journal of Children's Services. 8(2) 